\title{
Cold-Air-Pool Structure and Evolution in a Mountain Basin: Peter Sinks, Utah
}

\author{
Craig B. Clements \\ NOAA Cooperative Institute for Regional Prediction, Department of Meteorology, University of Utah, Salt Lake City, Utah \\ C. DAVID WhiteMAN \\ Pacific Northwest National Laboratory, Richland, Washington \\ JOHN D. HOREL \\ NOAA Cooperative Institute for Regional Prediction, Department of Meteorology, University of Utah, Salt Lake City, Utah
}

(Manuscript received 20 February 2002, in final form 26 August 2002)

\begin{abstract}
The evolution of potential temperature and wind structure during the buildup of nocturnal cold-air pools was investigated during clear, dry, September nights in Utah's Peter Sinks basin, a 1-km-diameter limestone sinkhole that holds the Utah minimum temperature record of $-56^{\circ} \mathrm{C}$. The evolution of cold-pool characteristics depended on the strength of prevailing flows above the basin. On an undisturbed day, a $30^{\circ} \mathrm{C}$ diurnal temperature range and a strong nocturnal potential temperature inversion $(22 \mathrm{~K}$ in $100 \mathrm{~m})$ were observed in the basin. Initially, downslope flows formed on the basin sidewalls. As a very strong potential temperature jump (17 K) developed at the top of the cold pool, however, the winds died within the basin and over the sidewalls. A persistent turbulent sublayer formed below the jump. Turbulent sensible heat flux on the basin floor became negligible shortly after sunset while the basin atmosphere continued to cool. Temperatures over the slopes, except for a 1-2-m-deep layer, became warmer than over the basin center at the same altitude. Cooling rates for the entire basin near sunset were comparable to the $90 \mathrm{~W} \mathrm{~m}^{-2}$ rate of loss of net longwave radiation at the basin floor, but these rates decreased to only a few watts per square meter by sunrise. This paper compares the observed cold-pool buildup in basins with inversion buildup in valleys.
\end{abstract}

\section{Introduction}

Atmospheric structure in valleys during clear, undisturbed nighttime periods is strongly affected by the along-valley wind system. As the air in the valley cools to temperatures below that of the air at the same elevation farther down the valley or over the adjacent plain, a down-valley wind is initiated. Air that is cooled within a valley and carried down the valley by this wind system must be replaced by potentially warmer air that sinks into the valley from above. The warm sinking air acts as a brake on the down-valley wind system and reduces the nighttime cooling in the valley. In contrast in enclosed basins, the lack of an along-valley wind system with its associated sinking of warmer air allows the basin air to cool more rapidly. Thus, basins are generally found to have minimum temperatures lower than those experienced in adjacent or nearby valleys. Although this much is known about basins, there have, to date, been few observational studies in enclosed basins to inves-

Corresponding author address: C. David Whiteman, Pacific Northwest National Laboratory, P.O. Box 999, Richland, WA 99352.

E-mail: dave.whiteman@pnl.gov tigate the processes responsible for the high rates of nighttime cooling in topographic situations in which along-valley winds play little or no role in slowing the cooling.

Current theory of cold-pool formation in valleys and basins (e.g., Geiger 1965) emphasizes the role of longwave radiation loss and the downward flux of sensible heat from the overlying atmosphere to counter this loss. This produces a cold-air layer over the slopes, which subsequently drains downslope into the nascent coldair pool, causing it to grow and cool. Previous research has been conducted to determine the causes of extreme minimum temperatures in basins, particularly in regions plagued by intense frost damage. Sauberer and Dirmhirn (1954, 1956), for example, investigated minimum temperatures and the changing atmospheric temperature structure in Austria's Gstettner-Alm sinkhole where flows within the sinkhole were weak and the prevailing synoptic winds did not penetrate into the cold pool. Other investigations in Japan (Magono et al. 1982; Yoshino 1984; Maki and Harimaya 1988; Mori and Kobayashi 1996; Iijima and Shinoda 2000) described the cooling of basins, attempted to resolve the processes 
that contribute to the formation of cold-air pools, and studied the seasonal variation in cold-pool characteristics. Because the basins were not sufficiently enclosed, advective effects complicated the results and made it difficult to identify the major cooling processes. Several studies have focused on the heat budgets of basins during nighttime (Maki et al. 1986; Kondo et al. 1989; Whiteman et al. 1996). Whiteman et al. (1996) found stronger down-valley flows than expected in Colorado's Sinbad basin, which is drained by a narrow canyon. The heat budget there was complicated by the difficult-tomeasure advection terms and could not be successfully closed. They concluded that strong (but unmeasured) downward turbulent heat fluxes produced by shear in the downslope flows on the sidewalls may have been responsible for the imbalance. Model simulations by Fast et al. (1996) supported this view.

This paper describes a short field campaign in a small, topographically simple basin to document the evolution of basin temperature and wind structure during the nighttime cold-air-pool buildup period under conditions in which the cooling is not suppressed by along-valley flows. The basin chosen, the Peter Sinks basin of Utah, holds the extreme minimum temperature record for Utah $\left(-56^{\circ} \mathrm{C}\right)$ and has produced the second coldest temperature recorded in the contiguous United States (Pope and Brough 1996). The basin was chosen because the extreme cold temperatures recorded there suggested that it is a good example of a closed basin in which along-valley winds are absent. The exploratory campaign was designed to determine whether this is the case by observing the evolution of the vertical atmospheric structure in the basin with the goal of making an initial evaluation of the physical mechanisms that lead to the cold-air pools and low minimum temperatures. Analyses of our field campaign data call into question many of the tenets of the current theory of cold-pool formation and raise some interesting research questions that will require additional field studies and model simulations.

This study is focused on gaining a better understanding of the development of cold pools under almost ideal topographic conditions in which the complicating effects of advection are minimized. One motivation for the investigation is the expectation that a better general understanding of cold-pool evolution may have important practical implications for the forecasting of cold-pool formation and dissipation, one of the more difficult forecasting problems in the western United States (Smith et al. 1997). There, and in many other parts of the world, cold pools are responsible for many wintertime and nighttime air-pollution episodes (e.g., Allwine et al. 1992), producing persistent cold weather events that, when accompanied by clouds, drizzle, and light rain, have important effects on visibility and produce significant adverse effects on transportation and health.

\section{Experimental site, instrumentation, and design}

\section{a. Experimental site}

The site chosen for the experiments was the Peter Sinks basin of northern Utah (Fig. 1). The basin, a 1$\mathrm{km}$ oval-shaped limestone sinkhole, has a floor elevation of $2500 \mathrm{~m}$, is surrounded by higher terrain of approximately 150-m relief, and, because it is located on the crest of the Bear River Range, has a particularly simple drainage area. There are no major tributary valleys, but the basin has two lobes. Experiments were conducted in the northernmost lobe. Slopes surrounding the basin are relatively uniform. The eastern slope has an angle of about $11^{\circ}$, the northern slope is about $13^{\circ}$, and the western slope is about $28^{\circ}$. Vegetation in the basin is sparse, because it is grazed in the summer by cattle and sheep. Vegetation type depends primarily on slope aspect. The eastern slope contains mostly short grasses $(<0.5 \mathrm{~m})$ and sagebrush $(\sim 0.75 \mathrm{~m})$. The northern slope supports a sparse distribution of sagebrush and small shrubs $(<0.5 \mathrm{~m})$. The lower half of the western slope contains medium-sized talus; short conifers grow on the upper two-thirds of this slope. The basin floor has short grasses $(<0.1 \mathrm{~m})$ and bare soil. Conifers are found on the basin crest. As noted by investigators for other sinkholes (e.g., Iijima and Shinoda 2000), there is a distinct "vegetation inversion" in the basin, with no trees at the lowest elevations. Soil type depends on location but generally consists of loose clay and sandy alluvium.

The Peter Sinks basin is completely enclosed to an altitude of $35 \mathrm{~m}$ above the basin floor (Fig. 2). Above this elevation there are open gaps on the basin's periphery. The lowest gap, to the south of the basin, is the pass between the two lobes of the basin. A low saddle, $55 \mathrm{~m}$ above the basin floor, is present on the eastern slope. The drainage area within the basin as a function of height (Fig. 3) was determined by plainmeter from a 1:24 000 map of the basin by tracing the contours enclosed within the basin boundary shown in Fig. 1b. Cummulative basin volume as a function of height was obtained by summing the volumes of atmospheric layers between terrain contours calculated as the volume of the frustum of a cone. The total drainage area of the basin is $2.25 \mathrm{~km}^{2}$ and the total volume is $0.25 \mathrm{~km}^{3}$. At the average crest height, $h_{c}=88 \mathrm{~m}$ (Fig. 2), the drainage area $A_{x y}\left(h_{c}\right)$ is $1.9 \mathrm{~km}^{2}$ and the volume $v\left(h_{c}\right)$ is $0.1 \mathrm{~km}^{3}$.

\section{b. Description of experimental periods}

A meteorological field campaign was conducted in the Peter Sinks from 8 to 12 September 1999. This period had no precipitation, clear nights (daytime cumulus only on 9 and 10 September), very dry soil conditions with much dust on the dirt roads, low atmospheric moisture contents, and no fog or dew. Three experiments were conducted during this period. Experiment 1 (EXP1), which had the most ideal synoptic conditions, took place on the evening of 8 September and 


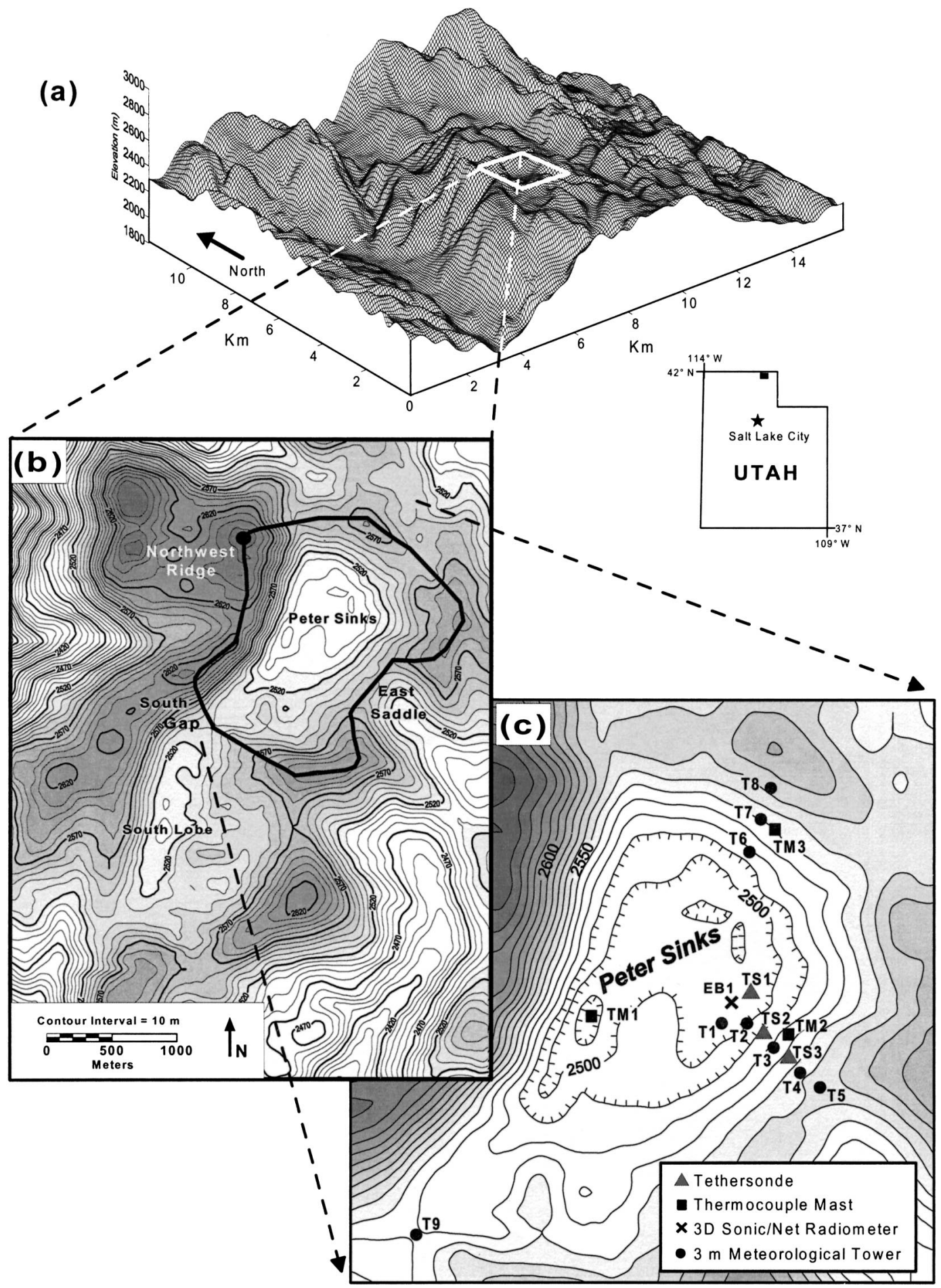

FIG. 1. Experiment location in northern Utah. Topographic features are shown by (a) the 3D wire-frame plot and (b), (c) two topographic maps. Experimental sites are shown in (c). The basin periphery is indicated (thick black line) in (b). The black dot is the starting point for the plot of ridge-crest elevation in Fig. 2. 


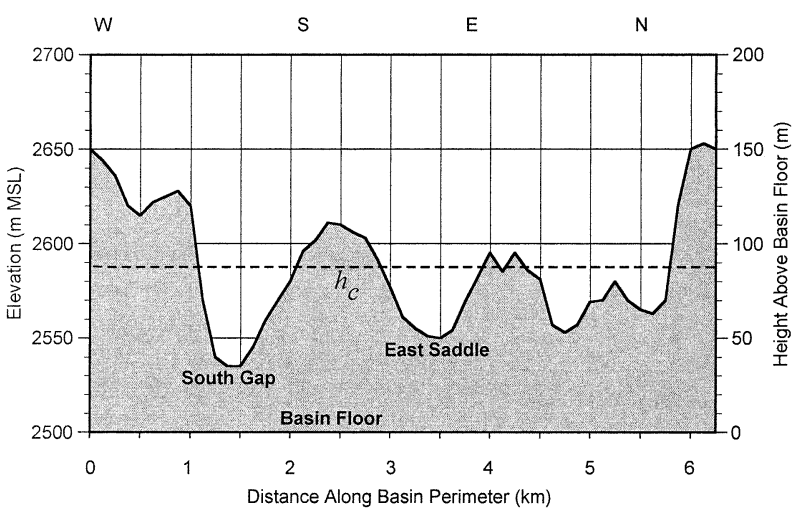

FIG. 2. Ridge-crest elevation as a function of distance counterclockwise around the basin periphery along the thick black line in Fig. $1 \mathrm{~b}$. The dashed line is the mean crest height $h_{c}$.

continued until midmorning the following day. A weak upper-level $(500 \mathrm{hPa})$ ridge situated over the western United States allowed for clear skies and light crestlevel winds $\left(<3 \mathrm{~m} \mathrm{~s}^{-1}\right)$ during this experiment. Routine Salt Lake City, Utah, rawinsonde soundings taken 140$\mathrm{km}$ south-southwest of the Peter Sinks indicated that during EXP1 the 700-hPa winds (approximately $500 \mathrm{~m}$ above the basin floor) were light and from the northwest. Astronomical sunset and sunrise occurred at 1849 and 0601 mountain standard time (MST) during EXP1; local sunset and sunrise times varied with location in the basin.

Experiment 2 (EXP2) took place during the evening of 10 September but was halted when winds at crest level increased to 5-6 $\mathrm{m} \mathrm{s}^{-1}$ and the cold pool dissipated prematurely as the ridge weakened and a weak, fastmoving short-wave trough passed to the north of Utah; 700-hPa winds were southwesterly before the trough and shifted to northwesterly by the morning of $11 \mathrm{Sep}-$ tember.

Experiment 3 (EXP3) was conducted during the evening and morning transition periods of 11-12 September, although no observations were taken in the middle of the night. The inversion formed somewhat later in the evening than normal because of gusty, daytime winds, but these winds decreased as evening progressed. EXP3 was influenced by a large-scale $500-\mathrm{hPa}$ trough centered over the Midwest; 700-hPa winds remained from the northwest but dropped below $4 \mathrm{~m} \mathrm{~s}^{-1}$ and became westerly by the morning of 12 September.

\section{c. Instrumentation}

Instrument locations are shown in Fig. 1c; further details on the sites, instruments, and instrument characteristics are provided in Table 1 . The instrumentation was installed primarily on the eastern and northern slopes; the steep western slope was not instrumented because of poor access. The instrumentation included three tethersondes, nine meteorological towers, three

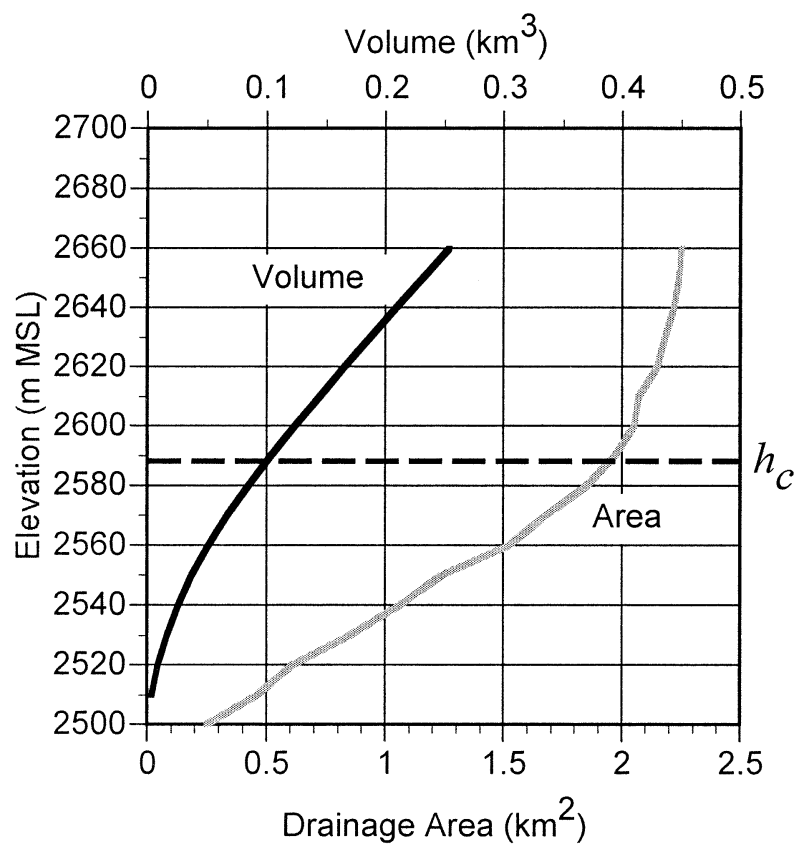

FIG. 3. Basin drainage area and volume as a function of elevation. The dashed line is the mean crest height $h_{c}$.

temperature masts, and a surface energy budget station consisting of a net radiometer and a 3D sonic anemometer. The tethersondes were arranged along the fall line of the eastern slope, with two on the slope and one on the basin floor at the foot of the slope. The meteorological towers were located on lines running up both the eastern and northern slopes. An additional tower was placed on the pass between the two lobes of the sinkhole to determine whether cold-pool mass was exchanged between the two lobes. Twelve-meter masts equipped with thermocouples were placed on both the northern and eastern slopes. A shorter 4-m thermocouple mast was placed in a small sinkhole on the basin floor to measure the coldest temperatures in the sinkhole. The surface energy budget station was installed on the basin floor near the tethersonde. Instrument locations were selected primarily to document the evolution and spatial variability of the temperature and flow fields and to characterize the flows that enter the cold pool from the slopes.

Several limitations of the instruments must be mentioned. Because the tethered balloon is used as a wind vane to sense wind direction and the sonde is flown about $2 \mathrm{~m}$ below the balloon, the wind direction data come from a different height than the other meteorological variables (including wind speed) sampled by the sonde. In addition, because the rigging of the balloon does not allow the sonde to be brought closer than $2 \mathrm{~m}$ to the ground, the lowest $2 \mathrm{~m}$ of the basin atmosphere is not sampled by the tethersondes. The threshold speed of the tethersonde's 3-cup anemometer is $0.25-0.30 \mathrm{~m}$ $\mathrm{s}^{-1}$ (C. Quire 2002, personal communication). The 


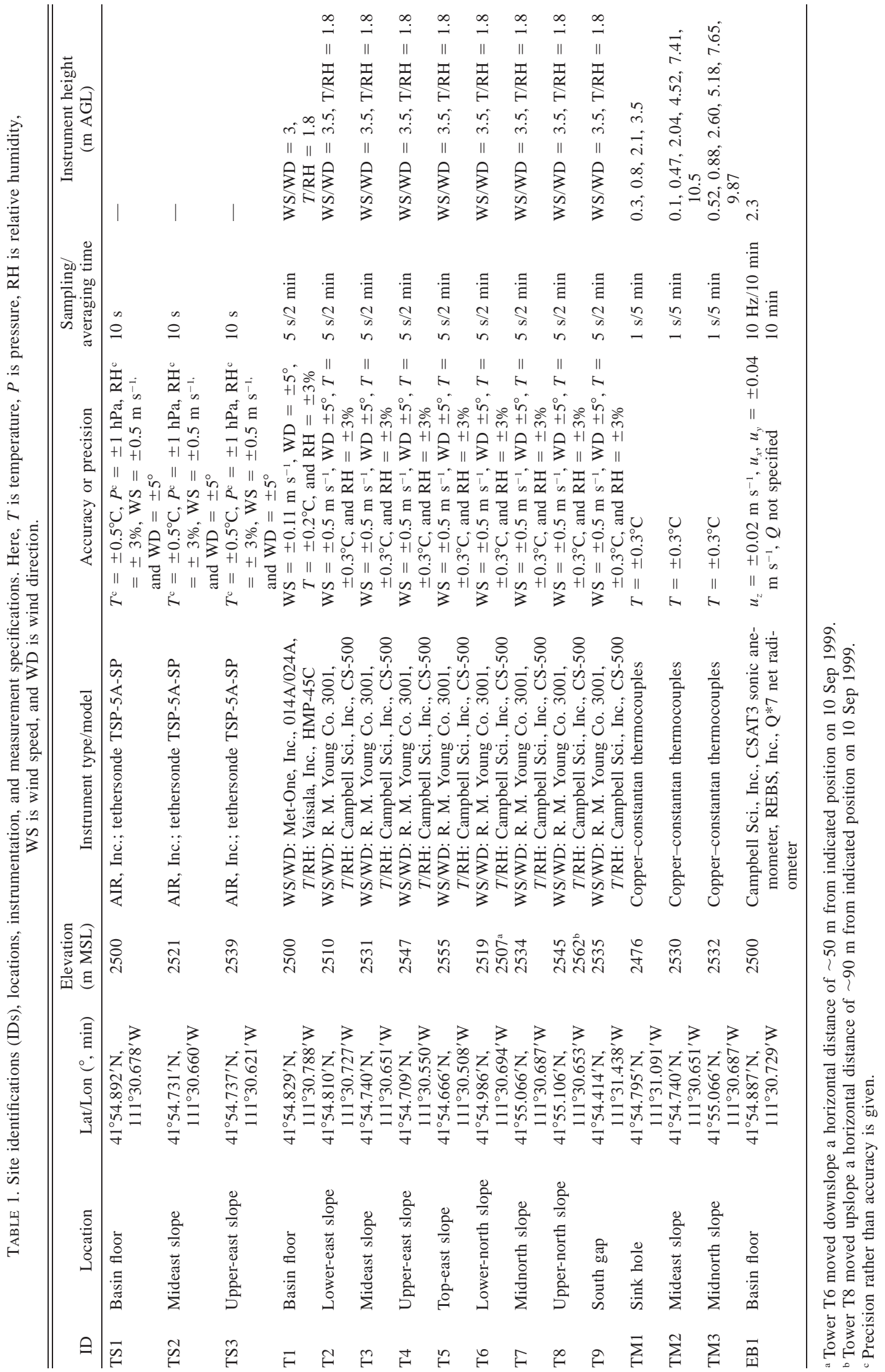


threshold speed $\left(0.45 \mathrm{~m} \mathrm{~s}^{-1}\right)$ and height $(3 \mathrm{~m})$ of the anemometers at the meteorological stations generally proved unsuitable for measuring the weak and shallow nighttime downslope flows above the basin slopes. Also, the lowest thermocouple on mast TM2 could not be shielded because of its proximity to the ground $(0.1 \mathrm{~m})$; all of the other thermocouples were enclosed in radiation shields.

Tethersonde sensors and mast thermocouples were calibrated before the experiment. Thermocouple temperatures agreed within $0.15^{\circ} \mathrm{C}$, and the sonde temperatures were within a range of $0.25^{\circ} \mathrm{C}$. Because of this good agreement, no corrections were applied to data from the individual sondes. Field intercomparisons of the sondes were made before each experiment. During instrument takedown on 12 September 1999, a comparison of average temperatures between $\mathrm{T} 3$ and one thermocouple from TM2 collocated in the radiation shield of T3 showed identical values.

\section{d. Tethersonde sounding procedures}

Tethersonde soundings were conducted simultaneously at the three sounding sites, and the slow ascents were coordinated by radio from the central receiving location at which data from all three sondes were logged. The time interval between soundings was varied depending on the observed rates of change in wind and temperature, for example, as short as $20 \mathrm{~min}$ in the early evening. The balloons were retrieved rapidly at the conclusion of the ascents, and the down-soundings were not used in subsequent analyses. At the ground, the sondes were allowed to equilibrate fully with the ambient air before the next ascent.

In the following section, the bulk characteristics of the cold-pool structure are investigated for the three subexperiments. This will be followed by a section investigating the detailed evolution of wind and temperature structure for the best undisturbed night, EXP1.

\section{Evolution of bulk cold-pool structure on three nights}

\section{a. Bulk cold-pool characteristics}

Temperatures from the five towers on the eastern sidewall (T1-T5) are shown in Fig. 4a for the entire experimental period. Figure $4 \mathrm{~b}$ shows the corresponding wind speed at T5, near the eastern gap. This site is the highest site having continuous wind data but does not necessarily sample the generally stronger winds above the basin, especially once the cold pool forms in the basin. Figure $4 \mathrm{c}$ presents the corresponding net radiation and sensible heat flux data collected at the basin floor. Temperature inversions (Fig. 4a) formed regularly in the basin. The strongest inversion and smoothest cycle of cooling observed during the experimental period occurred during the night of 8-9 September (EXP1). At the basin floor, T1 experienced a diurnal temperature range of nearly $30^{\circ} \mathrm{C}$ on this night, when winds at T5 were generally below $1 \mathrm{~m} \mathrm{~s}^{-1}$. The diurnal temperature range decreased with elevation in the basin, with the uppermost tower (T5) experiencing an $18^{\circ} \mathrm{C}$ temperature range. The temperature difference between the $\mathrm{T} 5$ and $\mathrm{T} 1$ towers, which are $55 \mathrm{~m}$ apart in elevation, reached $16^{\circ} \mathrm{C}$ at sunrise. On the night of 9-10 September, cooling at all elevations was much reduced when winds above the basin became stronger (reaching over $3 \mathrm{~m} \mathrm{~s}^{-1}$ at T5). Intermittent warming events occurred at all elevations in the basin as the warmer temperatures aloft were mixed downward. During the night of 10-11 September (EXP2), an inversion that began to build up during the evening broke around midnight when strong winds (reaching over $4 \mathrm{~m} \mathrm{~s}^{-1}$ at T5) mixed warmer air downward into the basin. On the night of 11-12 September (EXP3) a strong inversion similar to that of EXP1 formed in the basin, although its initiation was delayed by about $1 \mathrm{~h}$ by strong afternoon winds. The winds reached $10 \mathrm{~m} \mathrm{~s}^{-1}$ at $\mathrm{T} 5$ in midafternoon but dropped below $2 \mathrm{~m} \mathrm{~s}^{-1}$ by astronomical sunset.

Net radiation and sensible heat flux on the basin floor followed a regular pattern of behavior from night to night (Fig. 4c). Sensible heat flux was generally 0 during the nights, except for a period from 0300 to 0630 MST on 11 September when winds aloft broke into the basin, producing heat fluxes that dropped to $-60 \mathrm{~W} \mathrm{~m}^{-2}$, and a period each evening between local sunset and astronomical sunset (about 1700-1849 MST) when fluxes reached from -20 to $-30 \mathrm{~W} \mathrm{~m}^{-2}$. This latter period corresponded to the time during which downslope flows were strongest at the foot of the basin slopes. Near-zero sensible heat fluxes at night are not unexpected, because they have been reported by Whiteman et al. $(1989,1996)$ and Kondo et al. (1989) for other basins. Net radiation fell rapidly at local sunset, reaching its minimum of -80 to $-90 \mathrm{~W} \mathrm{~m}^{-2}$ by astronomical sunset and then increasing slowly to about $-60 \mathrm{~W} \mathrm{~m}^{-2}$ by astronomical sunrise. Previous investigators have found somewhat weaker nighttime net outgoing radiation in other lowerelevation basins and valleys under similar synoptic conditions (Whiteman et al. 1996; Iijima and Shinoda 2000).

The slow nighttime increase in net radiation is caused by the changing balance between the outgoing flux, which decreases as the ground surface cools, and the downward radiative flux, which comes from the warm sidewalls and the sky and which decreases at a slower rate during the night. The downward radiative flux is enhanced by the warm air mass at the top of the developing cold pool. The contribution to the downward radiative flux at the basin floor from the relatively warm sidewalls and warm air mass at the top of the basin cold pool is much greater than the contribution that would be received from a less obstructed sky, such as that found higher in the basin.

The evolution of the vertical structure of potential 


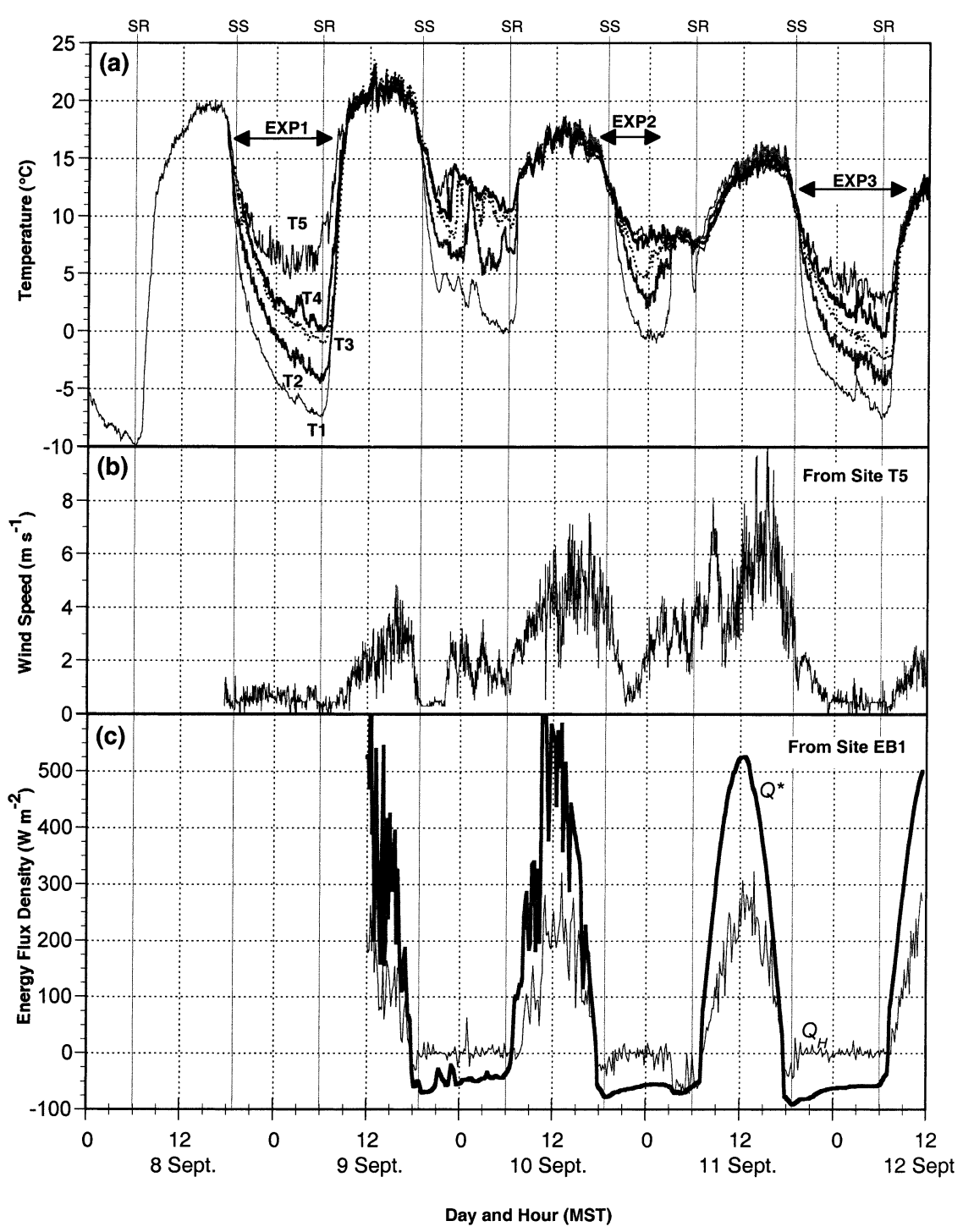

FIG. 4. Time series of (a) air temperature from towers T1-T5 on the east sidewall, (b) wind speed at tower T5 near the top of the east sidewall, and (c) net radiation $Q^{*}$ and sensible heat flux $Q_{H}$ at site EB1 on the basin floor. Experimental periods are indicated.

temperature and wind over the basin center during the cold-pool formation period is shown for selected soundings at approximately hourly intervals for each of the three experiments in Fig. 5. The vertical potential temperature profiles in all three experiments evolve following the schematic diagram of Fig. 6 in which a coldpool stable layer (CPSL) forms at the basin floor (see, e.g., the 1806 and 1844 MST soundings for EXP1 in Fig. 5) and deepens with time while its stability decreases slightly. The upward growth of the CPSL is rapid and its maximum depth stabilizes early in the evening while the air within the CPSL continues to cool through the remainder of the night. At the same time, a temperature jump or capping inversion layer (CIL) forms and strengthens above the CPSL. The two layers, together, make up the cold-air pool (CAP), that is, the pool of cold air enclosed by the basin terrain. The strengthening of the CIL is a consequence of the more rapid rate of cooling at the base of the CIL inside the basin relative to the slower rate of cooling at its top in the free atmosphere above the basin. The different signs of the stability trends in the CPSL and CIL cause a characteristic "blufflike" shape of the potential temperature profiles.

Some distinct differences in wind and temperature profile evolution occur in the different experiments (Fig. 5). In EXP1, the temperature profile shows a dramatic cooling in the lowest $70-80 \mathrm{~m}$ during the cold-pool formation period, and the wind speeds are very light within that layer $\left(<1 \mathrm{~m} \mathrm{~s}^{-1}\right)$. The CAP is well defined, with a CPSL extending to $75 \mathrm{~m}$ and a strong CIL extending from 75 to $120 \mathrm{~m}$ above ground level (AGL). 

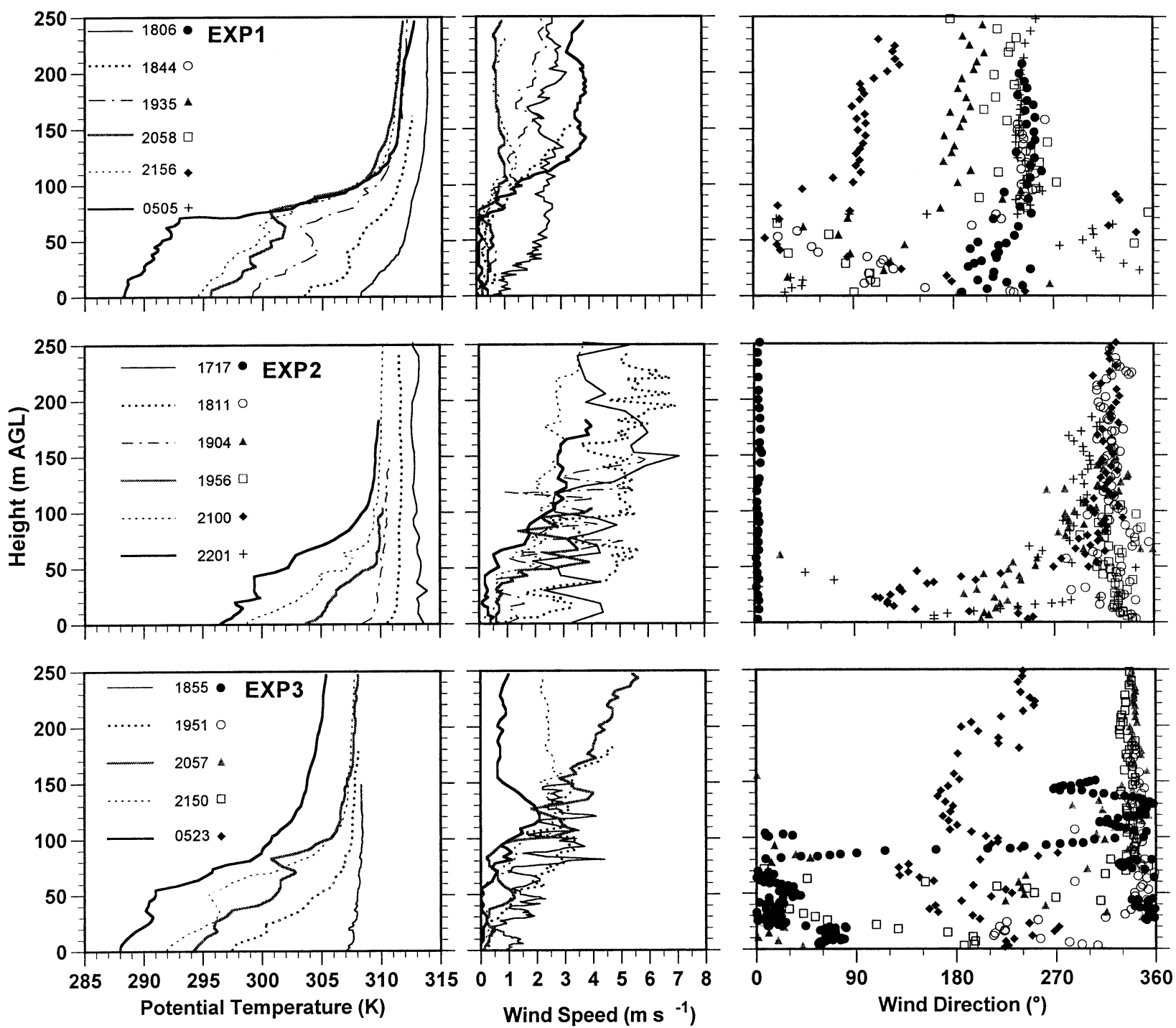

FIG. 5. Vertical profiles of potential temperature, wind speed, and wind direction at site TS1 on the basin floor for selected times (MST) during each of the three experiments.

The bluff structure is best seen in the late evening and early morning profiles (i.e., 2156 and 0505 MST). In contrast, EXP2 initially had strong winds $\left(\sim 4-6 \mathrm{~m} \mathrm{~s}^{-1}\right)$ that were clearly mixed down into the basin from above the basin. The winds in the basin soon settled to approximately $1 \mathrm{~m} \mathrm{~s}^{-1}$ within the building stable layer. EXP2 did not cool as dramatically during the evening (Fig. 4) as the other two experiments did, was lacking the well-defined bluff structure of EXP1, and showed a slower increase in inversion top height with time during the buildup phase. In EXP3, temperatures were colder than the previous night and more cooling was observed aloft than in EXP1 and EXP2. Gustiness and wind direction shifts occurred through the depth of the basin initially, but later in the evening (2057 MST) the gustiness diminished and flows within the CPSL became very light $\left(<1 \mathrm{~m} \mathrm{~s}^{-1}\right)$. By $0523 \mathrm{MST}$, the top of the
CPSL approached the 60-m level and was surmounted by a CIL that extended to approximately $140 \mathrm{~m}$.

\section{b. Changes in heat storage in the basin atmosphere}

The decrease in basin atmospheric heat storage $S$ from an initial adiabatic profile (potential temperature $\theta_{0}=$ constant) in late afternoon per unit of basin horizontal area can be calculated for a given vertical profile of potential temperature $\theta(z)$, as follows:

$$
S=-\frac{\int_{0}^{h} c_{p} \rho(z)\left[\theta_{0}-\theta(z)\right] A(z) d z}{A_{h}}\left(\mathrm{~J} \mathrm{~m}^{-2}\right),
$$

where $c_{p}$ is the specific heat of air at constant pressure, $\rho(z)$ is the air density, $A(z)$ is the basin drainage area, 


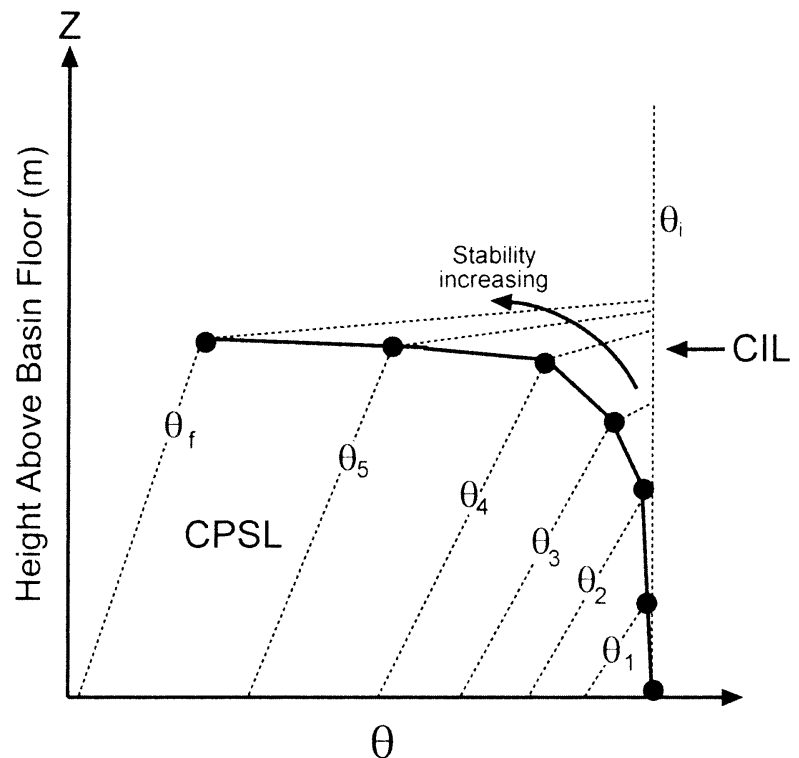

FIG. 6. Schematic diagram of the buildup of the CAP over the basin center during the evening transition period. The CAP is composed of two sublayers, the CPSL and the CIL. The black dots indicate the top of the CPSL at each sounding time. Dashed lines are potential temperature profiles, where $\theta_{i}$ is the well-mixed late-afternoon sounding and $\theta_{f}$ is the sunrise sounding.

and potential temperature is assumed to be horizontally homogeneous within the basin. For the three experiments, $S$ has been calculated numerically for each of the soundings at site TS1. The integrations were made to a height of $h=120 \mathrm{~m}$ because this level remains above the major cooling that takes place in the basin. The basin drainage area at this height is $A_{h}=2.17 \mathrm{~km}^{2}$ (see Fig. 3). The integrations were performed using 10$\mathrm{m}$ height intervals, and the constant potential temperatures and times of the initial afternoon soundings were estimated from surface temperature data and the first afternoon soundings for each of the three experiments. The potential temperatures and times for EXP1, EXP2, and EXP3 were 313.6 and 1730, 313.3 and 1700, and 308.3 K and 1845 MST, respectively.

The loss of heat from the basin atmosphere began between 1700 and 1900 MST in the three experiments, accumulating to values of about $1 \mathrm{MJ} \mathrm{m}^{-2}$ in EXP1 and EXP3 by sunrise. During the windy night of EXP2, the cumulative loss was a linear function of time through about $2100 \mathrm{MST}$ at the rate of $27 \mathrm{~W} \mathrm{~m}^{-2}$. An increase in the rate of loss began after this time, but observations were ended soon thereafter. In EXP3, the growth of the cold pool was delayed by strong afternoon winds and the rates of loss were erratic throughout the evening, averaging $45 \mathrm{~W} \mathrm{~m}^{-2}$. The loss of heat from the basin during EXP1 is thought to be most representative of a "pure" basin cold-pool formation on a night with weak winds aloft. The heat-loss values in Fig. 7a for EXP1 were fitted with a third-order polynomial curve, which was differentiated to obtain the curve for the rate of

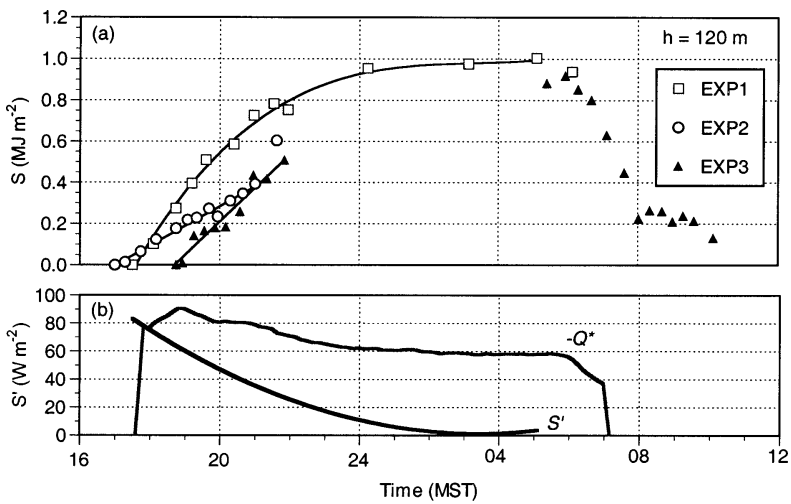

FIG. 7. (a) Cumulative loss of heat storage $S$ from the basin atmosphere $\left(\mathrm{MJ} \mathrm{m}^{-2}\right)$ for the three experiments as computed to a height of $120 \mathrm{~m}$ from TS1 potential temperature soundings (see text). Also shown is a third-order polynomial fit to the EXP1 data. (b) Rate of loss of heat storage $S^{\prime}\left(\mathrm{W} \mathrm{m} \mathrm{m}^{-2}\right)$ for EXP1 as obtained by differentiating the fitted curve in (a). Also shown is the rate of net radiative loss at the surface $-Q^{*}$ during EXP3.

heat loss in Fig. 7b. The rate of loss decreased during the night from $83 \mathrm{~W} \mathrm{~m}^{-2}$ at local sunset to values less than $10 \mathrm{~W} \mathrm{~m}^{-2}$ after midnight. The rates of loss of sensible heat from the basin's atmosphere are surprisingly large in the early evening, approaching the rate of outgoing net radiation near the surface. Net outgoing radiation was not measured during EXP1, but it is expected to be similar to EXP3, for which the radiative loss increased from 0 at 1745 MST to 90 at 1900 MST and then decreased to $60 \mathrm{~W} \mathrm{~m} \mathrm{~m}^{-2}$ by midnight.

\section{Cold-pool buildup during EXP1}

In the previous section, selected potential temperature profiles from the basin center were used to illustrate the bulk evolution of the basin cold pool during the three experiments. In this section, detailed temperature and wind structure data from the three tethersonde sites for EXP1 are presented to develop a three-dimensional conceptual picture of the temperature and wind structure leading to cold-pool formation on this "ideal" night, which had weak background winds at ridge level. Selected data are also shown for EXP3 for which additional research equipment was operational and background winds, although stronger than in EXP1, were not as strong as during EXP2.

\section{a. Potential temperature structure}

The series of potential temperature soundings for EXP1 at the three tethersonde sites are presented in Fig. 8. The soundings show the strong nighttime cooling of the basin volume at all three sites and, with it, the development of a CIL, and a CPSL that extends down to the underlying basin floor or slope. A 5-25-m-deep turbulent sublayer occurs just below the CIL in the upper part of the CPSL. This turbulent sublayer, containing 


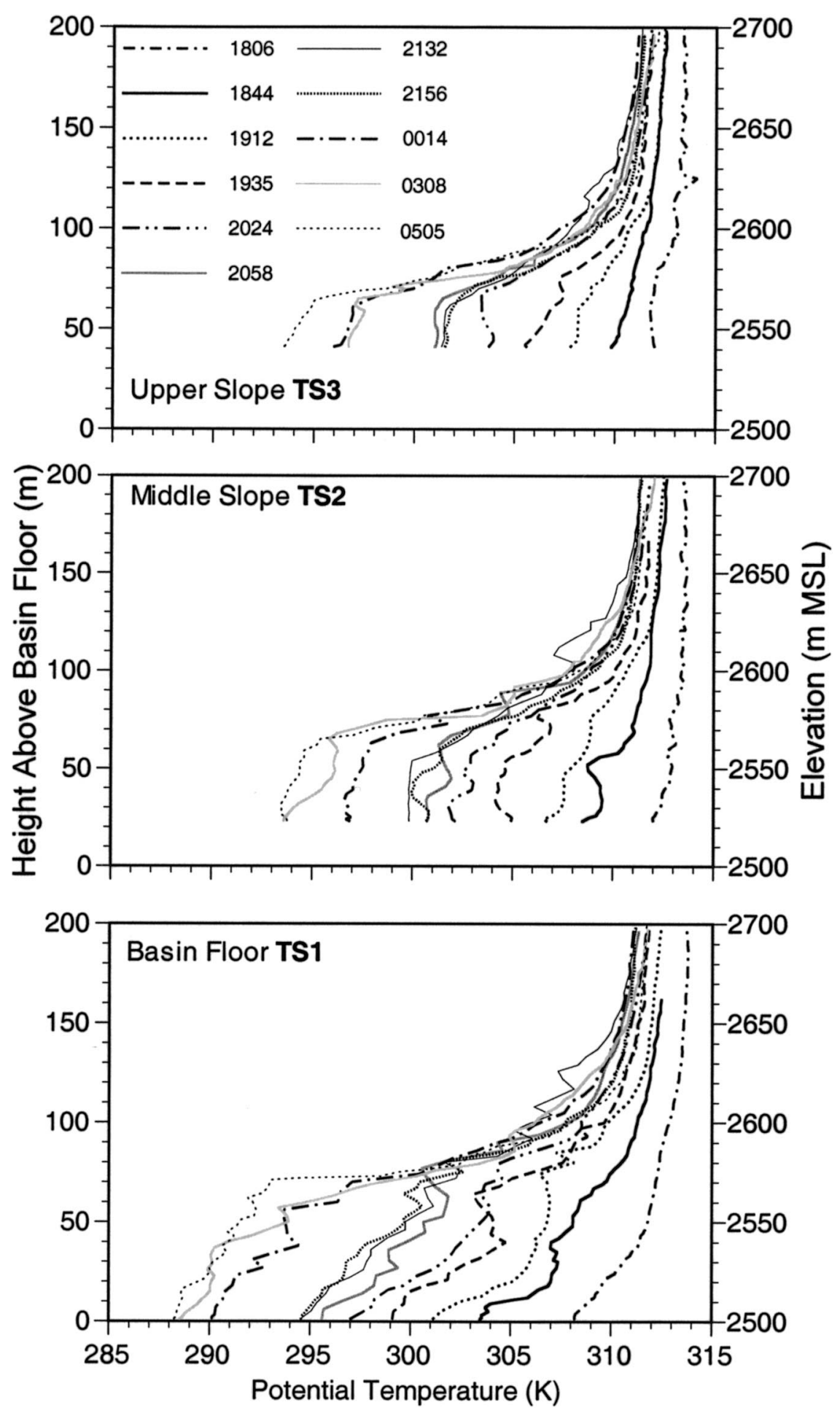

FIG. 8. Vertical profiles of potential temperature from (top) the upper slope (TS3), (middle) middle slope (TS2), and (bottom) the basin floor (TS1) for EXP 1. Sounding times (MST) are shown in the top panel. 

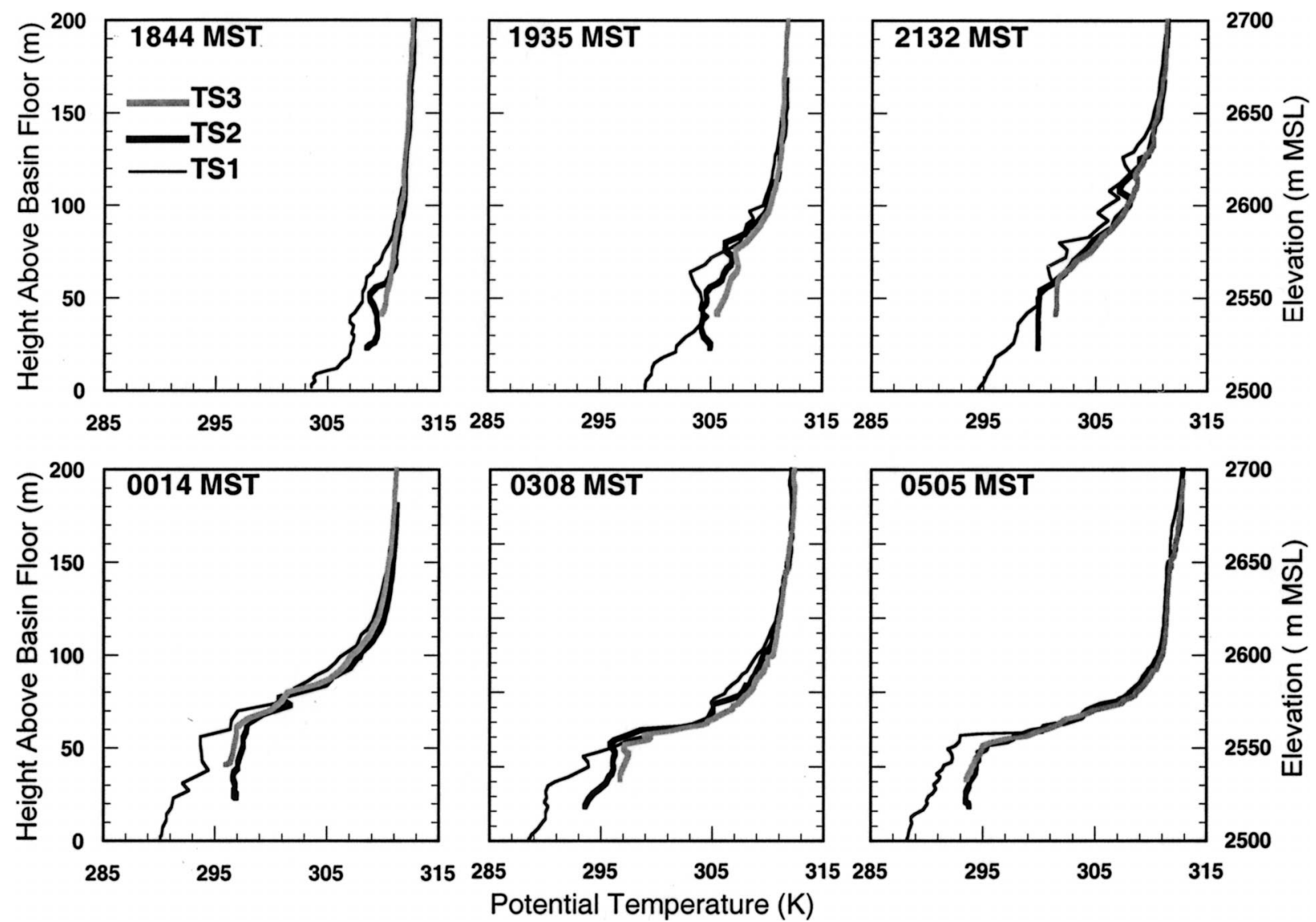

FIG. 9. Concurrent vertical potential temperature profiles from the three tethered balloon sites for selected sounding times during EXP1.

superadiabatic lapse rates, is a remarkable and unexpected finding that has not been previously reported. Elevated superadiabatic (SA) sublayers are rarely seen in atmospheric soundings, and one is present here in a basin cold pool—one of the most stable temperature structures on the earth. The stacked combination of CIL, SA, and CPSL produces distinctive S-shaped deformations in the profiles over the basin floor and sidewalls. A fourth layer, a $30-\mathrm{m}$-deep, strong stability sublayer of the CPSL seen right at the basin floor, disappears after the 2024 MST sounding. It is present only on the basin floor and does not extend high enough to be seen at sidewall sites TS2 and TS3. The temperature structure of the CIL and its height above the basin floor are similar at the three sites, indicating that the atmosphere is approximately horizontally homogeneous from sidewall to sidewall in this structural layer. The strongest cooling of the basin atmosphere is initially seen at the basin floor, but this cooling does not progress slowly upward as would be expected if cold air were converging over the basin floor. Rather, the height of the CIL base seems to be fixed very early in the sounding sequence and to change little with time.

Although the potential temperature structure above and within the CIL is horizontally homogeneous across the basin, significant horizontal differences in potential temperature and potential temperature gradient develop during the night below the base of the CIL, which is located about $65 \mathrm{~m}$ above the basin floor. These are seen most readily in Fig. 9, in which selected potential temperature profiles are plotted so that all three soundings at a given time are on the same panel. Potential temperatures above the sidewalls become progressively warmer than the air over the basin center and the vertical temperature gradient becomes weaker than in the same layers above the basin center. By sunrise, potential temperature differences reach $5 \mathrm{~K}$. This relative warming of the air over the sidewalls is one of the most surprising features of the observations. A temperature deficit above the sidewalls (along with its associated negative buoyancy and horizontal pressure gradient) is a necessary condition to produce the downslope flows (Wagner 1938; Magono et al. 1982; Doran and Horst 1983; Yoshino 1984) that are required for the slope-flow convergence theory of cold-pool buildup. Because the tethersondes were unable to make temperature readings within $2 \mathrm{~m}$ of the ground, thermocouple mast data at TM2 during EXP3 were investigated to determine if a temperature deficit was present at lower layers over the slope (Fig. 10). (TM2 was not installed for EXP1 but 


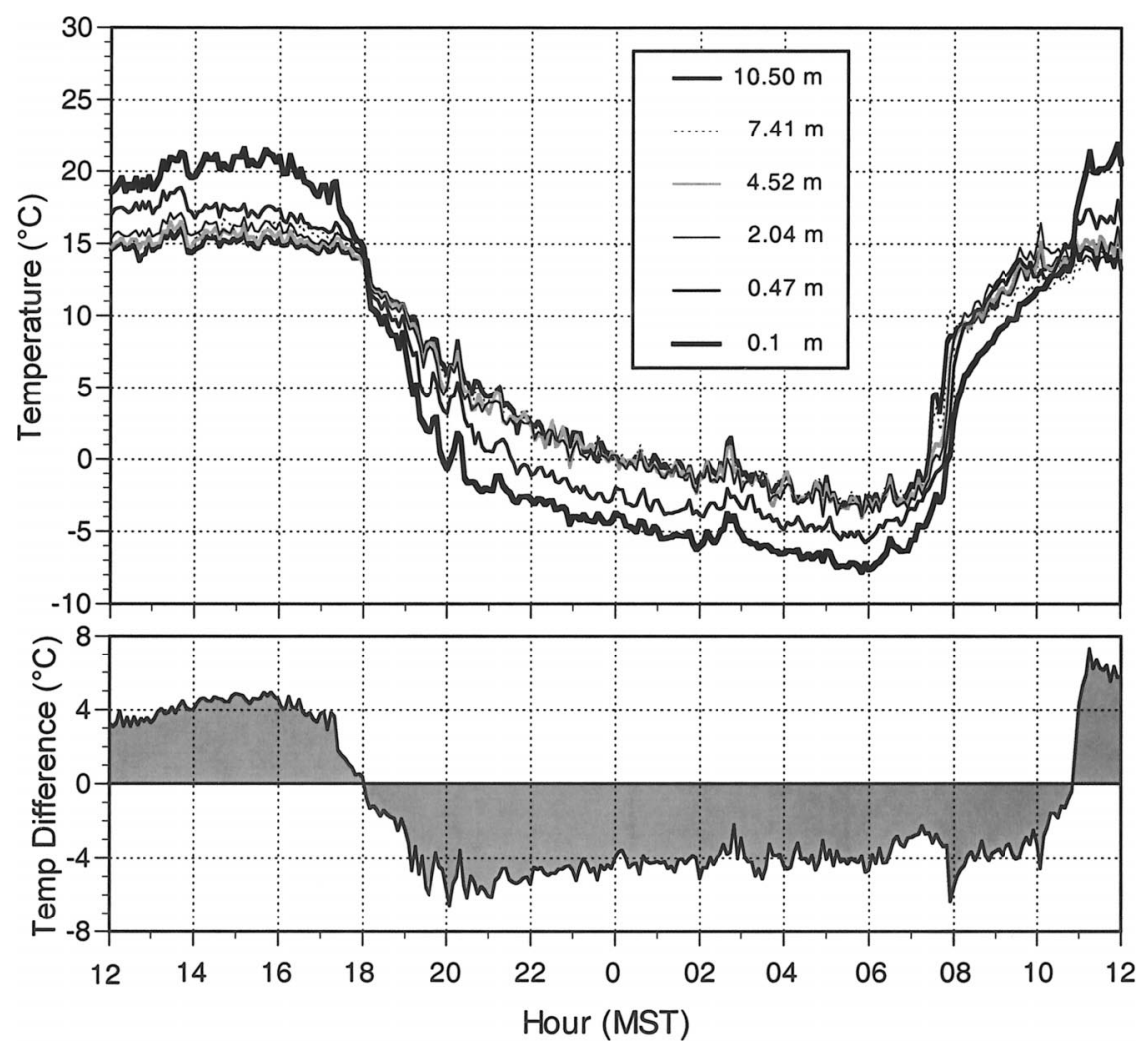

FIG. 10. Time series of (a) temperatures for EXP3 at the indicated altitudes above the eastern sidewall at TM2 and (b) the temperature difference between the 2.04- and 0.1-m levels.

was available for EXP3.) In conformance with the EXP3 tethersonde measurements, an approximately isothermal layer was observed above the slope between 2 and 10 $\mathrm{m}$ AGL, but also seen was a drop of temperature between the 2.04- and 0.1-m levels. This drop, initially $7^{\circ} \mathrm{C}$ in the early evening, decreased to $4^{\circ} \mathrm{C}$ by sunrise. Because the effective radiating temperature of the ground is expected to be below the air temperature at $0.1 \mathrm{~m}$, we might expect air temperatures to be even lower closer to the ground. Comparison of the $0.1-\mathrm{m}$ air temperature with the TS1-measured temperature over the basin center during EXP3 showed that the 0.1-m temperature was always at or below the temperature at the same height over the TS1 site. Thus, another surprising thing about the basin is that the temperature deficit above the slope is found only in the lowest $2 \mathrm{~m}$ AGL.

\section{b. Wind structure}

Vector winds for EXP1 are plotted in Fig. 11 on a time-height cross section, with heights plotted above ground level (left-hand scale of figure) and above mean sea level (MSL; right-hand scale) for each of the three sites. Winds were similar at all three sites above 2700 m MSL (not shown). Lines on the subfigures indicate boundaries between the CPSL, CIL, and free atmo- sphere as determined from the temperature structure, and shading identifies wind speeds $\leq 0.4 \mathrm{~m} \mathrm{~s}^{-1}$ and the SA sublayer. The top of the CIL, defined as the maximum height to which perceptible cooling extended above the basin, corresponds approximately to the highest elevations on the basin's periphery. Winds aloft were weak and variable in direction during the night, exceeding $3 \mathrm{~m} \mathrm{~s}^{-1}$ only at the higher altitudes just before sunrise. As the static stability increased within the basin (especially in the CIL), the winds in the CPSL fell below $0.4 \mathrm{~m} \mathrm{~s}^{-1}$ and became variable in direction.

The base of the CIL (Fig. 11), which corresponds to the top of the near-calm winds within the basin, was at approximately the same MSL height at all three sites, although it was slightly lower over the basin center at night and higher during the evening and morning transition periods. The CIL, considered as a temperature transition layer between the CPSL and the free atmosphere above the basin (section 3a), is also a wind transition layer, connecting the weak winds inside the basin to the stronger free tropospheric winds above the basin. The depth to which winds aloft penetrated downward into the high-stability CIL is somewhat surprising. This is not truly a downward penetration, however, because the CIL cannot be expected to extend outside the basin, and the atmosphere surrounding the basin had free tropospheric winds that could have been carried horizon- 

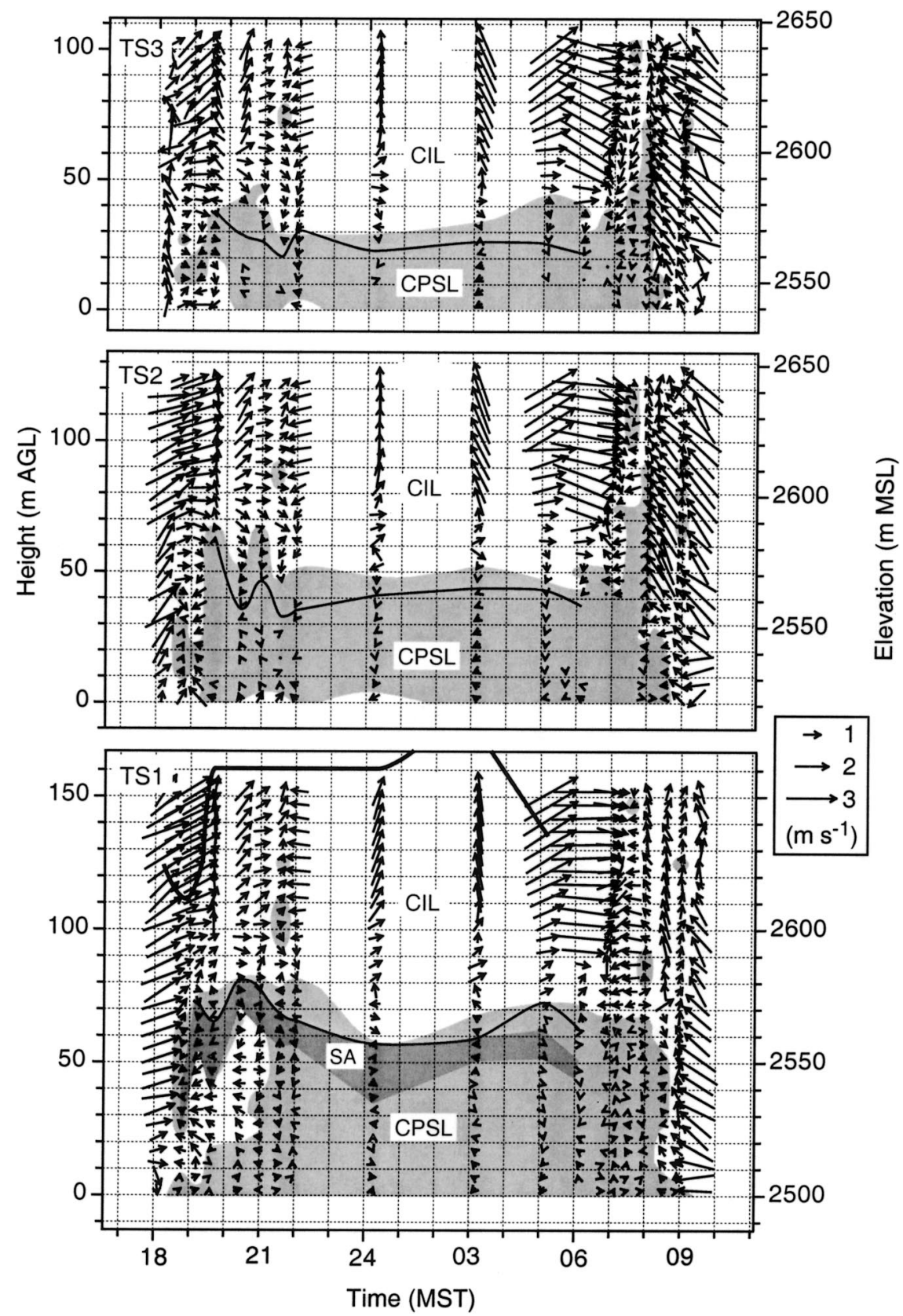

FIG. 11. Time-height cross sections of vector winds at 5-m height intervals from tethered balloon soundings at sites (top) TS3, (middle) TS2, and (bottom) TS1 during EXP1. Vector length indicates wind speed (see scale in legend); vector orientation indicates the wind direction at the time and height corresponding to the center point of the vector. A vector pointing straight up indicates a wind blowing from south to north, a vector pointing to the right blows from west to east, etc. Wind speeds less than or equal to $0.4 \mathrm{~m} \mathrm{~s}^{-1}$ have light gray shading; vectors are omitted when speeds are $0 \mathrm{~m} \mathrm{~s}^{-1}$. The dark gray shading indicates the superadiabatic sublayer. The boundaries between the CPSL and CIL (thin lines on the three subfigures), and the CIL and the free atmosphere (thick line on TS1 panel) are also shown.

tally into the CIL, especially through the gaps into the basin at the higher elevations (Fig. 3).

The downslope flows that form inside the basin during the first few hours of the buildup period are now examined. The downslope wind components (i.e., com- ponents of the measured wind speeds along the $135^{\circ}$ fall line of the eastern slope) are shown in Fig. 12 for the three tethersonde sites for soundings made from 1844 to 2024 MST. Southwesterly to northerly winds that were mixed down from above the basin were pre- 

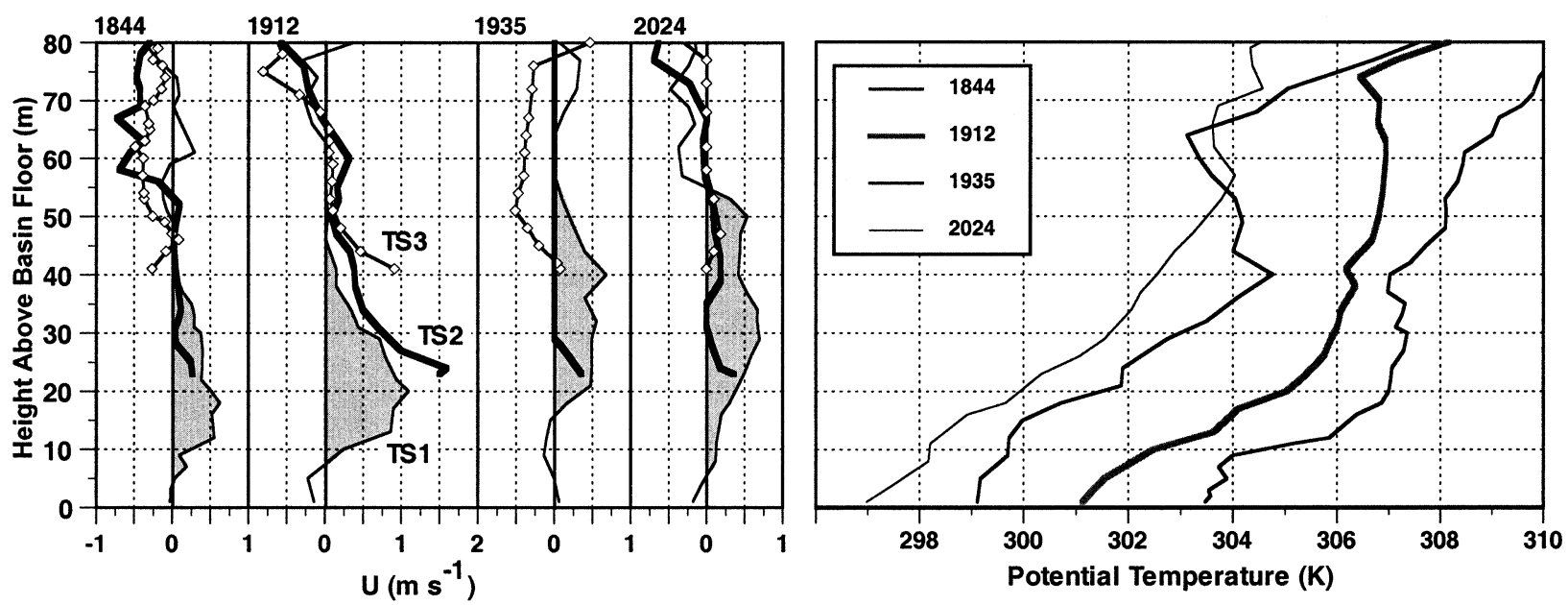

FIG. 12. Vertical profiles of (left) the downslope wind components at the TS1, TS2, and TS3 tethersonde sites and (right) potential temperatures at TS1 at 1844, 1912, 1935, and 2024 MST for EXP1.

sent in the basin before this time period, and winds over the slope and within the cold pool became very weak afterward. When interpreting the tethersonde observations, it is important to keep in mind that the lowestelevation wind directions (speeds) sensed by the tethered balloons were $4 \mathrm{~m}(2 \mathrm{~m})$ above the slope sites.

During the early cold-pool buildup period, very shallow $(<10 \mathrm{~m})$ and weak $\left(<0.5 \mathrm{~m} \mathrm{~s}^{-1}\right)$ jet like wind layers formed immediately above the eastern slope. There was a short period (1912 MST) when the flows became stronger and more energetic as a downslope surge occurred with peak velocities of $1.6 \mathrm{~m} \mathrm{~s}^{-1}$ at TS2 and 0.9 $\mathrm{m} \mathrm{s}^{-1}$ at TS3. At the time that these downslope flows were present on the sidewall, observations over the basin center (shaded profiles in Fig. 12) showed air flowing into the cold pool from the sidewall in an elevated, shallow $(10-20 \mathrm{~m})$ layer just above the top of preexisting surface-based stable layers that are shown in the corresponding potential temperature profiles of Fig. 12. The peak slope flow at $3 \mathrm{~m}$ AGL ( $24 \mathrm{~m}$ above the basin floor) at TS2 was approximately at the same height as the flow found at $22 \mathrm{~m}$ over the basin floor at TS1 (Fig. 12). These shallow downslope-directed jets were present at the same time at all tethersonde sites, and the height of the jet profile rose above the basin floor as the stable layer on the basin floor grew deeper. This rise in height (seen by tracking the shaded profiles) suggests that the flows coming off of the sidewall became detached from the sidewall and ran out over the basin center when they reached the elevation of the top of the strong stability layer. The flows over the slopes decreased significantly in depth and strength at 1935 and 2024 MST and were too light to be measured with the tethersondes and slope towers after that time; observers on the slopes, however, reported very light downslope flows in the lowest meter or two above the slope, with speeds, determined by throwing dust into the air and timing its movement, of $0.2-0.3 \mathrm{~m} \mathrm{~s}^{-1}$.
With respect to the theory of cold-air-pool growth by the convergence of downslope flows, it must be recognized that the observed slope flows were fully contained within the CPSL and, thus, are not evidence for mass coming into the cold pool from slopes that are above the cold pool. Thus, their presence does not support the convergence theory. However, the (weak) turbulence in the downslope flow layer within the CPSL may enhance the sensible heat flux to the underlying slope, thereby cooling the air above the slope.

\section{Discussion}

This discussion will be focused primarily on the EXP1 cold-pool buildup period, because there are many surprising features there that can be contrasted with the better-known temperature-structure evolution in valleys. First, however, one of the initial goals of the experimental design was to determine whether the basin has an effective along-valley wind system or, alternately, is connected to its surroundings by advection. Observations in the lowest outlets (T5, East Saddle, and T9, South Gap) indicate that there was little transport near the surface out of the basin. In addition, the extremely weak horizontal winds within the basin show advection into the basin from its surroundings to be weak. The lowest elevations in the basin are effectively isolated from the assuredly warmer air at the same elevations surrounding the basin. However, at the upper elevations of the basin, it is likely that cold air produced inside the basin may drain out of the basin through the gaps, requiring a sinking of warmer air into the upper basin. Although this flow could not be measured, the base of the CIL ( $\sim 65 \mathrm{~m}$ above the basin floor) attains a height that may represent an equilibrium between the sinking of air into the basin and the flow of cooled air out of the basin gaps that is controlled by the vertical distribution of the cross-sectional area of the basin openings 
(see Fig. 3). If this is the case, the loss of cold air through the basin openings may be partly responsible for the decrease in the rate of basin cooling with time during the night.

The structural layers within the basin cold pool are particularly interesting, because they are so different from previous reports of temperature structure in valleys. The CIL is a particularly interesting feature. Valleys do not exhibit such temperature jumps at the top of nocturnal inversions but, rather, the temperature increases with height to approach asymptotically the free air temperature above the valley (an exception occurs in winter when strong warm-air advection occurs above a cold pool confined within a valley). The elevated turbulent or SA sublayer found at the top of the CPSL has already been mentioned as an apparently unique feature of basin meteorological behavior that has not, to our knowledge, been previously observed. This shallow layer is persistent and occurs in a region in which horizontal winds are very weak. Because no strong gradients in wind direction or speed occurred across this layer at any of the three tethersonde sites, we can reject the hypothesis that this layer was produced by differential temperature advection, which would have required warmair advection at the base of the layer and cold-air advection at its top. The wind data do not support the hypothesis that the SA sublayer is a zone in which downslope flows leave the sidewalls and converge over the basin center to cause the cold pool to grow (nor do we see such a layer in the CIL above). The variation in depth and strength of this layer from sounding to sounding is reminiscent of the statistical sampling problem experienced when making profiles of the entrainment zone at the top of an unstable boundary layer. In the case of the basin, the turbulent layer could be produced by "negative" convection in which cold air forms at the top of the CPSL and convects downward into the underlying CPSL, with a consequent overturning of the air in this layer. Such behavior would cause an upward turbulent flux of heat out of the top of the CPSL and could help to explain the continuous net cooling of the CPSL during the night.

Winds aloft have a strong impact on the evolution of the cold pool. As evidenced by extensive wind-scoured snow fields and large cornices in the lee of the East Saddle still present during the summer, the basin, on the crest of a high-mountain barrier, is usually affected by strong winds and the resulting turbulence and wave motions produced by the terrain on the basin's ridgelines. On the windiest night (EXP2), which likely reflects much calmer conditions than those typically present in the basin, the slow and regular increase in depth of the cold pool, the absence of a well-marked temperature jump at the inversion top, and the near-constant rate of heat loss (Fig. 7) are in contrast to the other, nearly calm, nights. These windy night features are similar to patterns of inversion growth in valleys with moderate or strong along-valley winds (Vergeiner and Dreiseitl
1987; Whiteman 1990). The slower growth of the inversion top and lower rate of heat loss may be caused by the strong winds stripping cold air off of the higherelevation slopes or by turbulent erosion at the cold pool's top; the near-linear shape of the temperature profiles within the inversion could be produced by shear and mixing, which would enhance the downward turbulent heat flux at the basin floor and sidewalls.

Some interesting questions arise in regard to the rate of cooling of the air in the basin relative to the measured net radiation and sensible heat flux. Especially puzzling is how the basin atmosphere could be cooling at a rate in the early evening that is similar to the rate of loss of longwave radiation at the surface (Fig. 4). Radiative cooling of the basin volume, after all, would require a radiative flux divergence, not simply a surface radiative flux, and radiative flux cannot be expected to fall to zero at the top of the basin atmosphere. Thus, turbulent sensible heat flux must play an important role during this early part of the cold-pool buildup period. This hypothesis is supported by the observation that sensible heat flux is significant in the early buildup period on the basin floor (Fig. 4).

Except for a shallow skin flow on the sidewalls, the slope flows essentially die within about $2 \mathrm{~h}$ after the inversion buildup begins. Thus, the cold-pool buildup in the Peter Sinks does not fit the conceptual model that nighttime cooling and inversion buildup come from cold air that forms on the slopes, drains into the basin, and converges over the basin bottom. The progressive warming of the air over the sidewalls relative to the temperatures over the basin center explains why the downslope flows end. The near-neutral temperature structure that develops over the sidewalls cannot be produced by heating at the ground or by mixing due to shear, because the sidewall is not heated at night and there is essentially no wind or shear stress above the sidewall. It might, therefore, be produced by negative convection and overturning by a source of cooling at the top of the neutral layer, which could also explain the decreasing ambient stability over the basin center.

\section{Conclusions}

The buildup of cold-air pools in a small, high-altitude, mountain basin was investigated using data collected during three clear September nights. The small, enclosed Peter Sinks basin was chosen for the experiments to minimize the effects of advection. In valleys, downvalley flows and compensatory subsidence and warming greatly complicate the interpretation of atmospheric mass and heat-budget computations. As expected, under clear skies and weak synoptic flow, the strong nighttime stability and the weak horizontal flows inside the basin isolated the basin from the surrounding ambient environment.

The basin cooled quickly each night, producing strong temperature inversions that were confined within 
the $150-\mathrm{m}$ relief of the basin. The temperature and wind structure evolution in the basin varied from night to night, depending on the strength of the winds above the basin. Strong winds at crest level delayed cold-pool formation and, on one night, eroded an already-formed cold pool by turbulent mixing.

The cold pool developed fully in depth within 2-3 h following sunset. While the free air above the basin cooled very little the air within the basin continued to cool throughout the night. The potential temperature profiles maintained a two-layer cold-air pool structurea lower cold pool stable layer that was capped by an extremely stable capping inversion layer. In the upper part of the CPSL just below the CIL, a 5-25-m-deep, elevated, turbulent sublayer developed and persisted for the entire night. At first, downslope flows became detached from the sidewalls and ran out over the basin center on top of a shallow stable layer in the lowest tens of meters above the basin floor. These flows ceased about $2 \mathrm{~h}$ after sunset, and winds in the entire basin became too weak to measure accurately. After the CPSL grew to nearly the effective height of the basin $(\sim 88$ $\mathrm{m})$, its growth ceased, presumably because air cooled within the basin flowed out of the lowest-altitude gaps as the cold pool deepened.

Cold-pool buildup in the Peter Sinks did not fit the usual conceptual model of cold-pool formation in valleys and basins in which the cold pool deepens as cold air running down the sidewalls converges within the pool. New results from the Peter Sinks basin experiments include the following:

- The formation of a persistent, elevated, turbulent or superadiabatic sublayer within one of the most stable atmospheric structures on the earth, a basin cold pool, is very surprising. We hypothesize that this layer is produced by negative convection or overturning by a source of cooling at the top of the layer.

- Another surprising result, not previously documented in other shallow basins, is that the air over the basin sidewalls gradually became warmer $(1-5 \mathrm{~K})$ than the air over the basin center at the same altitude during the night. Only in a 1-2-m-deep layer adjacent to the ground is the air above the slope colder than the air at the same level over the basin center. The relatively warm air over the slopes does not support the continued development of downslope flows, a major link in the slope-flow convergence theory of cold-pool buildup.

- Downslope flows played only a minor role in the formation of the cold-air pool. The flows over the sidewalls became extremely weak $\left(\sim 0.2 \mathrm{~m} \mathrm{~s}^{-1}\right)$ and shallow $(\sim 1 \mathrm{~m})$ within $2 \mathrm{~h}$ after sunset, leading to a stagnant basin cold pool that, nonetheless, continued to cool for the rest of the night.

- Heat loss from the basin atmosphere on an undisturbed night is at an initial rate that is close to the net rate of longwave loss at the surface, but it decreases with time through the night. Rates of heat loss from the basin atmosphere were lower on windier nights.

- During periods of weak synoptic-scale flow, the surrounding terrain minimizes advective interactions between the basin and the ambient environment. The continued nighttime cooling of the basin atmosphere must be attributed to turbulent sensible heat flux divergence, radiative flux divergence, or a combination of the two. Turbulent sensible heat flux was significant on the basin floor during a 1.5-h period around sunset but became zero shortly thereafter as downslope flows (and, hence, turbulence) ceased on the basin sidewalls, suggesting that turbulent sensible heat flux divergence is supplanted by radiative heat flux divergence later in the cold pool.

Further analyses of the experimental data, collection of additional data, and radiative and dynamic model simulations will allow a more detailed diagnosis of the physical processes contributing to the heat and mass budgets of the Peter Sinks. We plan to use radiative transfer modeling in future analyses to investigate the relative roles of turbulent sensible heat flux divergence and radiative flux divergence for the heat budget of the Peter Sinks basin.

Acknowledgments. Dr. Jerry Allwine [Pacific Northwest National Laboratory (PNNL)] provided preexperiment tethersonde calibrations, essential in-field support, and postexperiment analysis advice. Burt Tanner and Ed Swiatek (Campbell Scientific, Inc.) provided a net radiometer and sonic anemometer, installed and operated them in the field, and provided processed data. Dan Judd (Judd Communications, Inc.) assisted with the programming and setup of the tower network. Dr. Al Astling (U.S. Army Dugway Proving Ground) and students and staff from the University of Utah; including Mark Beaty, Linda Cheng, Carol Ciliberti, Justin Cox, Lacey Holland, Galdino Mota, Steve Nesbitt, Mike Splitt, and Jebb Stewart, operated tethersondes and provided other essential field support. The Logan office of the WasatchCache National Forest is thanked for providing a special-use permit.

This research was supported by the U.S. Department of Energy (DOE) under the auspices of the Atmospheric Sciences Program of the Office of Biological and Environmental Research and was conducted at the University of Utah (DOE Grant No. DE-FG03-99ER62841) and at PNNL. PNNL is operated for the DOE by Battelle Memorial Institute. Additional support was provided by the University of Utah through Research Instrumentation Award No. 07919. One of the authors (C.B. Clements) was supported by a Graduate Research Environmental Fellowship funded by DOE's Global Change Education Program.

\section{REFERENCES}

Allwine, K. J., B. Lamb, and R. Eskridge, 1992: Wintertime dispersion in a mountainous basin at Roanoke, Virgina: Tracer study. J. Appl. Meteor., 31, 1295-1311. 
Doran, J. C., and T. W. Horst, 1983: Observations and models of simple nocturnal slope flows. J. Atmos. Sci., 40, 708-717.

Fast, J. D., S. Zhong, and C. D. Whiteman, 1996: Boundary layer evolution within a canyonland basin. Part II: Numerical simulations of the nocturnal flows and heat budgets. J. Appl. Meteor., 35, 2162-2178.

Geiger, R., 1965: The Climate near the Ground. Harvard University Press, $482 \mathrm{pp}$.

Iijima, Y., and M. Shinoda, 2000: Seasonal changes in the cold-air pool formation in a subalpine hollow, central Japan. Int. J. Climatol., 20, 1471-1483.

Kondo, J., T. Kuwagata, and S. Haginoya, 1989: Heat budget analysis of nocturnal cooling and daytime heating in a basin. J. Atmos. Sci., 46, 2917-2933.

Magono, C., C. Nakamura, and Y. Yoshida, 1982: Nocturnal cooling of the Moshiri Basin, Hokkaido in midwinter. J. Meteor. Soc. Japan, 60, 1106-1116.

Maki, M., and T. Harimaya, 1988: The effect of advection and accumulation of downslope cold air on nocturnal cooling in basins. J. Meteor. Soc. Japan, 66, 581-597.

—_ — — , and K. Kikuchi, 1986: Heat budget studies on nocturnal cooling in a basin. J. Meteor. Soc. Japan, 64, 727-740.

Mori, M., and T. Kobayashi, 1996: Dynamic interaction between observed nocturnal drainage winds and a cold air lake. J. Meteor. Soc. Japan, 74, 247-258.

Pope, D., and C. Brough, 1996: Utah's Weather and Climate. Publishers Press, $245 \mathrm{pp}$.

Sauberer, F., and I. Dirmhirn, 1954: Über die Entstehung der extremen Temperaturminima in der Doline Gstettner-Alm (On the occurrence of extreme temperature minimums in the Gstettner-Alm Doline). Arch. Meteor. Geophys. Bioklimatol., Ser. B, 5, 307326.
_ , and $ـ$ 1956: Weitere Untersuchungen über die kaltluftansammungen in der Doline Gstettner-Alm bei Lunz im Niederösterreich (Further investigations of the cold air buildup in the Gstettner-Alm doline near Lunz in lower Austria). Wetter Leben, 8, 187-196.

Smith, R., and Coauthors, 1997: Local and remote effects of mountains on weather: Research needs and opportunities. Bull. Amer Meteor. Soc., 78, 877-892.

Vergeiner, I., and E. Dreiseitl, 1987: Valley winds and slope windsObservations and elementary thoughts. Meteor. Atmos. Phys., 36, 264-286.

Wagner, A., 1938: Theorie und Beobachtung der periodischen Gebirgswinde (Theory and observation of periodic mountain winds). Gerlands Beitr. Geophys., 52, 408-449. (English translation: Whiteman, C. D., and E. Dreiseitl, 1984: Alpine meteorology: Translations of classic contributions by A. Wagner, E. Ekhart, and F. Defant. Rep. PNL-5141/ASCOT-84-3, Pacific Northwest Laboratory, Richland, WA, $121 \mathrm{pp}$ ).

Whiteman, C. D., 1990: Observations of Thermally Developed Wind Systems in Mountainous Terrain. Atmospheric Processes over Complex Terrain, Meteor. Monogr., No. 45, Amer. Meteor. Soc., $5-42$.

— , K. J. Allwine, M. M. Orgill, L. J. Fritschen, and J. R. Simpson, 1989: Deep valley radiation and surface energy budget microclimates. Part II: Energy budget. J. Appl. Meteor., 28, 427-437.

_- T. B. McKee, and J. C. Doran, 1996: Boundary layer evolution within a canyonland basin. Part I: Mass, heat, and moisture budgets from observations. J. Appl. Meteor., 35, 2145-2161.

Yoshino, M. M., 1984: Thermal belt and cold air drainage on the mountain slope and cold air lake in the basin at quiet, clear night. Geo J., 8.3, 235-250. 